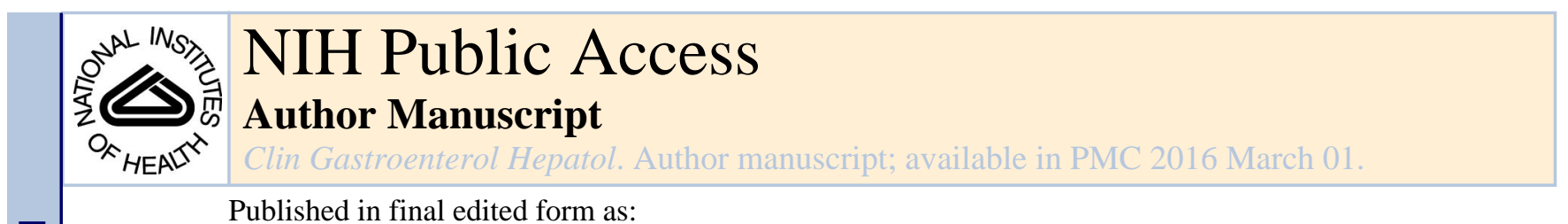

Published in final edited form as:

Clin Gastroenterol Hepatol. 2015 March ; 13(3): 452-458. doi:10.1016/j.cgh.2014.07.034.

\title{
Predictors of Response to Steroid Therapy for Eosinophilic Esophagitis and Treatment of Steroid-Refractory Patients
}

\author{
W. Asher Wolf, MD, MPH ${ }^{1,2}$, Cary C. Cotton, BA ${ }^{1}$, Daniel J. Green, BA ${ }^{1}$, Julia T. Hughes, \\ MD ${ }^{1}$, John T. Woosley, MD, PhD $^{3}$, Nicholas J. Shaheen, MD, MPH ${ }^{1,2}$, and Evan S. Dellon, \\ MD, MPH ${ }^{1,2}$ \\ ${ }^{1}$ Center for Esophageal Diseases and Swallowing, University of North Carolina School of \\ Medicine, Chapel Hill, NC \\ ${ }^{2}$ Center for Gastrointestinal Biology and Disease, Division of Gastroenterology and Hepatology, \\ Department of Medicine, University of North Carolina School of Medicine, Chapel Hill, NC \\ ${ }^{3}$ Department of Pathology and Laboratory Medicine, University of North Carolina School of \\ Medicine, Chapel Hill, NC
}

\begin{abstract}
Background \& Aims-Eosinophilic esophagitis (EoE) is commonly treated with swallowed (topical) corticosteroids (tCS). However, few factors have been described that predict outcomes of steroid therapy. We aimed to identify factors associated with non-response to tCS and report outcomes of second-line treatment for patients with steroid-refractory EoE.

Methods-We performed a retrospective cohort study, using the University of North Carolina

EoE Clinicopathologic Database to identify patients who received tCS for EoE from 2006 through

2013. Demographic, symptom, endoscopic, and histologic data were extracted from medical records. Immunohistochemistry was performed on archived biopsies. Responders and nonresponders to tCS were compared.
\end{abstract}

Results-Of 221 patients with EoE who received tCS, 71\% had endoscopic improvement, 79\% had symptomatic improvement, and 57\% had histologic response ( $<15$ eosinophils/high-power field). After multivariate logistic regression, esophageal dilation at the baseline examination predicted nonresponse (odds ratio [OR], 2.9; 95\% CI, 1.4-6.3), and abdominal pain predicted

\footnotetext{
(C) 2014 The American Gastroenterological Association. Published by Elsevier Inc. All rights reserved.

Corresponding Author: Evan S. Dellon MD, MPH, CB\#7080 Bioinformatics Building1, 130 Mason Farm Rd. UNC-CH, Chapel Hill, NC 27599-7080, Phone: (919) 966-2513, Fax: (919) 843-2508, edellon@med.unc.edu.

Publisher's Disclaimer: This is a PDF file of an unedited manuscript that has been accepted for publication. As a service to our customers we are providing this early version of the manuscript. The manuscript will undergo copyediting, typesetting, and review of the resulting proof before it is published in its final citable form. Please note that during the production process errors may be discovered which could affect the content, and all legal disclaimers that apply to the journal pertain.

Disclosures: Dr. Dellon has received research funding from AstraZeneca and Meritage, and is a consultant for Aptalsis, Novartis, Receptos, and Regeneron. None of the other authors have any conflicts of interest to disclose.

Author Contributions (all authors approved the final draft): Asher Wolf: analysis and interpretation of data, drafting the manuscript, Cary Cotton: acquisition of data, technical expertise, critical review of the manuscript, Daniel Green: acquisition of data, critical review of the manuscript, Julia T. Hughes: acquisition of data, critical review of the manuscript, John T. Woosley: study supervision, critical revision of the manuscript, Nicholas J. Shaheen: study supervision, critical revision of the manuscript, Evan S. Dellon: study concept and design, data interpretation, study supervision, critical revision of the manuscript
} 
response (OR for nonresponse, $0.31 ; 95 \% \mathrm{CI}, 0.12-0.83$ ); no other clinical features were predictive. Based on immunohistochemical analysis, higher levels of tryptase $\left(244\right.$ mast cells $/ \mathrm{mm}^{2}$ vs $157, P=.04)$ and eotaxin-3 (2425 cells $/ \mathrm{mm}^{2}$ vs $\left.239, P=.02\right)$ were associated with steroid response, but levels of major basic protein were not. Among 27 steroid-refractory patients, a mean of 2 additional therapies were tried; only $48 \%$ of the patients eventually responded to any secondline therapy.

Conclusions-Based on a retrospective analysis of a large group of patients with EoE, only $57 \%$ have a histologic response to steroid therapy. Baseline esophageal dilation and decreased levels of mast cells and eotaxin-3 predicted which patients would not respond to therapy; immunohistochemistry might therefore be used to direct therapy.

\section{Keywords}

eosinophilic esophagitis; corticosteroids; refractory; therapy; biomarkers

\section{Introduction}

Eosinophilic esophagitis (EoE) is a chronic, immune-mediated disorder of the esophagus defined by esophageal dysfunction and eosinophil infiltration into the esophageal mucosa in the absence of competing causes of esophageal eosinophilia. ${ }^{1-3}$ Swallowed ("topical") corticosteroids (tCS) are routinely used for treatment. ${ }^{4-9}$ While these medications successfully treat the majority of patients, a substantial minority of patients will have incomplete response. ${ }^{4,7}$

The predictors of successful steroid treatment have not been well explored. Whether demographic factors or endoscopic phenotypes of $\mathrm{EoE}^{10}$ are associated with treatment outcomes is unknown. Similarly, evidence supports a role for food and environmental allergies in the development of EoE, ${ }^{11-14}$ but the outcomes of patients with and without allergies have not been systematically explored. While the role of biomarkers in EoE is actively being explored, their utility for predicting treatment response has not been established. ${ }^{15-18}$ We have previously shown that immunohistochemical (IHC) staining for major basic protein (MBP), tryptase, and eotaxin-3 can discriminate EoE from gastroesophageal reflux disease (GERD), ${ }^{19,20}$ though it is unknown whether these markers at baseline could predict response to tCS.

The aims of this study were to determine the frequency of non-response to topical steroid treatment in EoE and to identify clinical, endoscopic, histologic, and immunohistochemical predictors of response. Further, we sought to describe the success of second line therapies in patients refractory to $\mathrm{tCS}$.

\section{Methods}

\section{Patients, data sources, and outcomes}

We performed a retrospective cohort analysis of patients at University of North Carolina (UNC) Hospitals from 2006-2013. Patients with EoE of any age were identified from the UNC EoE Clinicopathologic Database. ${ }^{20,21}$ For inclusion, patients had to have EoE by 
consensus guidelines ${ }^{1-3}$ including a diagnostic endoscopy while on high dose proton pump inhibitor and undergo treatment with swallowed tCS (fluticasone or budesonide for all study participants). In our practice, the first line course of tCS is either budesonide (0.5-1 mg twice daily, depending on patient age, with the aqueous formula mixed into a slurry with $5 \mathrm{~g}$ of sucralose $)^{5,9}$ or fluticasone (440-880 mcg twice daily, depending on patient age). ${ }^{4,7}$ Patients are instructed not to eat or drink anything for 60 minutes after swallowing the medication. Patients were typically treated for approximately 8 weeks prior to reassessment with esophagogastroduodenoscopy (EGD). Further endoscopies were dependent on patient symptoms and response to therapy, typically occurring at 8 week intervals until control of disease.

Data were abstracted from the UNC electronic medical record. Using standardized data collection tools, we recorded patient demographics, symptoms, comorbidities, baseline and follow-up endoscopy findings, baseline and follow-up eosinophil counts on esophageal biopsy, and therapeutic regimen. Patient symptoms were assessed prior to the diagnostic endoscopy and before treatments such as dilation or steroids. Eosinophil counts were previously determined for clinical purposes and were recorded as the maximum number of eosinophils per high-power field (eos/hpf; hpf size $=0.24 \mathrm{~mm}^{2}$ ) from pathologist review. Outcomes included symptom response (dichotomous patient-reported subjective improvement [yes/no]), endoscopic improvement (abstracted from endoscopy reports based on endoscopist's global assessment), and post-treatment eosinophil count. Because there is no consensus on the histologic cut-point to determine treatment response, ${ }^{3,22}$ an eosinophil count $<15$ eos/hpf was considered a response to therapy for the purpose of this analysis and was the main histologic outcome. We used the term "complete response" to describe only those patients with elimination of esophageal eosinophilia ( 0 eos/hpf). Patients who did not have a repeat endoscopy but who had clinical follow-up data with symptom outcomes were included in the symptom outcomes only.

To assess second-line treatment in steroid non-responders, we identified steroid refractory patients. They were defined as those who had $>30$ eos/hpf on repeat endoscopy and any one of the following: failure to have a symptomatic response, failure to have an endoscopic response, or requirement for esophageal dilation at presentation. A cutoff of $30 \mathrm{eos} / \mathrm{hpf}$ minimized misclassification occurring near the diagnostic cutpoint of $15 \mathrm{eos} / \mathrm{hpf}$ and to isolate those with more severe disease. Dilation was included because there were a group of patients with persistent esophageal eosinophilia but relief of symptoms attributable to dilation.

\section{Immunohistochemistry Staining}

IHC was performed for MBP, eotaxin-3, and tryptase on a subset of randomly selected patients with baseline tissue blocks available using previously described methodology. ${ }^{19,20}$ Briefly, IHC was performed using a high volume automated system (Bond Autostainer, Leica Microsystems, Norwell, MA) according to the standard protocol. Slides were deparaffinized with xylene and antigen retrieval was achieved with pepsin (20 mins) for MBP, and with Bond-Epitope Retrieval solution (citrate, $\mathrm{pH}=6$, AR9961) for eotaxin-3 and tryptase. Slides were incubated with the primary antibody of interest, incubated with a 
peroxidase-labeled secondary antibody, stained with a diaminobenzidine chromogen, and then counterstained with hematoxylin. The primary antibodies included: anti-MBP (mouse, clone BMK 13, 1:100 dilution; AbD Serotec, Kidlington, UK and Raleigh, NC); antieotaxin-3 (goat, no. 500-P156G, 1:100 dilution; PeproTech, Rocky Hill, NJ, USA), and a mouse anti-human mast cell tryptase primary antibody (Clone AA1; \#M7052; 1:3000 dilution; Dako, Carpinteria, CA). The slides were digitized and viewed with Aperio ImageScope (Aperio Technologies, Vista, CA). The maximum density of stain-positive cells in the esophageal epithelial layer, measured in cells $/ \mathrm{mm}^{2}$, was determined after examination of five microscopy fields.

\section{Data Analysis}

All data was analyzed using SAS version 9.3 (Cary, NC). Bivariate analyses were performed with chi-square testing for categorical variables. Because all continuous variables were nonnormally distributed, the Wilcoxon two-tailed $t$ approximation was used.

For construction of logistic regression models to predict steroid non-response, all variables at the $\mathrm{p}<0.2$ level on bivariate testing were included with the exception of esophageal narrowing. Narrowing was excluded in favor of dilation because the two variables represent related features of the esophagus, but dilation has less subjectivity. Stepwise reduction was performed until only variables at the $p<0.05$ level remained. The main effects model was then adjusted for variables which influenced treatment response but which did not reach statistical significance. Odds ratios derived from the main effects model and from the adjusted model are reported. This study was approved by the UNC Institutional Review Board.

\section{Results}

We identified 221 patients with EoE who were treated with a tCS during their course of care. The mean age was $25.6 \pm 18$ years, $83 \%$ were white, and $70 \%$ were male (Table 1 ). The predominant symptom at the time of diagnosis was dysphagia (70\%). Prior to diagnosis, patients had symptoms for an average of $7.5 \pm 9.3$ years, and co-existing allergic illness was common (58\%). One-quarter required dilation at initial endoscopy. Baseline eosinophil count was $79 \pm 66$ eos/hpf.

Budesonide was the most common therapy (63\%) with the remainder treated with fluticasone (Table 2). The average total daily dose of budesonide was $1686 \mathrm{mg}(2077 \pm 576$ $\mathrm{mg}$ in patients $\geq 18,1194 \pm 474 \mathrm{mg}$ in patients <18), and fluticasone was $1100 \mathrm{mg}(1412 \pm 513$ $\mathrm{mg}$ in patients $\geq 18,566 \pm 296 \mathrm{mg}$ in patients $<18$ ).

\section{Response to steroid therapy and predictors of non-response}

Repeat endoscopy to assess the effect of steroid therapy was performed on 193 (87\%) patients, and 137 (71\%) had an improved endoscopic appearance. Of the 193 repeat endoscopies, 189 (98\%) included biopsies. Those biopsies demonstrated that 108 (57\%) patients had $<15$ eos/hpf, while the remaining 81 (43\%) showed $\geq 15 \mathrm{eos} / \mathrm{hpf}$ and were considered non-responders. Additionally, follow-up symptom data were available on 190 patients, 150 of whom (79\%) had a symptomatic response to tCS. 
Responders did not differ from non-responders for the majority of presenting symptoms, symptom duration prior to diagnosis, rates of allergic illness, or baseline eosinophil counts (Table 1). However, non-responders had baseline EGDs that more frequently showed esophageal narrowing ( $28 \%$ vs $12, \mathrm{p}=0.005$ ) and required dilation ( $37 \%$ vs $19, \mathrm{p}=0.006)$. There was no significant difference in the type or dose of steroid used (Table 2).

On multivariate logistic regression, after adjustment for age, allergic disease, and baseline eosinophil count, only the need for dilation predicted steroid non-response (OR 2.9, 95\% CI [1.4-6.3]) while abdominal pain at presentation was associated with therapeutic response (OR for non-response 0.31, 95\% CI [0.12-0.83]) (Table 3).

\section{Immunohistochemical Markers for Predicting Response to TCS}

To assess the utility of MBP, eotaxin-3, and tryptase for predicting response to tCS, 40 baseline esophageal biopsies were randomly selected with 20 from patients who responded $(<15 \mathrm{eos} / \mathrm{hpf})$ and 20 who did not. The characteristics of this patient subset were similar to the overall study population, with the exception of post-treatment eosinophil count. Responders were $31 \pm 15$ years, $70 \%$ were male, $95 \%$ were white, the baseline maximum eosinophil count was $80 \pm 64 \mathrm{eos} / \mathrm{hpf}$, and the post-treatment count was $3 \pm 4$. The nonresponders were $31 \pm 11$ years, $70 \%$ were male, all were white, the baseline eosinophil count was $97 \pm 86 \mathrm{eos} / \mathrm{hpf}$, and the post treatment count was $75 \pm 21$. On IHC staining, the median tryptase density was greater in steroid responders ( 244 mast cells $/ \mathrm{mm}^{2}$ vs 157 , $\mathrm{p}=0.04$ ) as was eotaxin- 3 density $\left(2425\right.$ cells $/ \mathrm{mm}^{2}$ vs $\left.239, \mathrm{p}=0.02\right)$. MBP density did not differ between the two groups (1064 cells $/ \mathrm{mm}^{2}$ in responders vs 1715 in non-responders, $\mathrm{p}=0.54$ ) (Figure 1).

\section{Second-line Therapies in Refractory Patients}

Of the 57 refractory patients identified, 27 (47\%) underwent subsequent second-line therapy. The 30 patients not receiving second-line therapy either declined or were lost to follow up. In this refractory group (mean age $26,52 \%$ male, $74 \%$ white), baseline eosinophil count was $95 \pm 77$ eos/hpf and after steroid therapy was $85 \pm 32$. A mean of 2 (range 1-7) additional therapies were prescribed after failing tCS (Table 4). The most common was dietary therapy using a targeted or six food elimination diet. This was tried by $16(59 \%)$ of the 27 patients who received second line therapies and resulted in response ( $<15$ eos/hpf) in six (38\%). No treatment resulted in response in more than half of patients, and the overall rate of response was $48 \%$. After treatment, these patients achieved an average esophageal eosinophil count of $26 \pm 26$ eos/hpf. Notably, seven (26\%) of these patients acknowledged medication noncompliance. The rate of successful second-line therapy did not differ significantly between patients who endorsed non-compliance and those who did not (43\% vs 50\%, $\mathrm{p}=0.74$ ).

Serial esophageal dilation was used adjunctively in the treatment of refractory patients. Of 57 refractory patients, $19(33 \%)$ underwent dilation at their diagnostic EGD. Fifty-three underwent a second EGD with $25(47 \%)$ receiving dilation at that visit. Of 36 undergoing a third EGD, 18 (50\%) were dilated, and of 26 undergoing a fourth EGD $16(62 \%)$ received dilation. The majority of refractory patients required at least one dilation $(31,53 \%)$, and 
among the 53 patients undergoing two or more EGDs, 23 (46\%) required 2 or more dilations. In this population, dilation was safe with no esophageal perforations reported.

\section{Discussion}

While tCS remain the primary pharmacologic treatment for EoE, ${ }^{4,17,23}$ little is known about clinical or biomarker predictors of response, and there are few data on second-line treatments in steroid-refractory patients. In this study of a large cohort of EoE patients treated with tCS, we examined predictors of response to steroid therapy in EoE. There are several notable findings. First, histologic non-response to tCS was common. More than $40 \%$ of patients had persistent esophageal eosinophilia defined as $\geq 15 \mathrm{eos} / \mathrm{hpf}$, despite recommended doses of corticosteroids. This highlights the need for both improved topical steroid formulations and novel non-steroid agents to more effectively treat EoE. This rate of steroid non-response is similar to past randomized studies (38-50\% for fluticasone; $13-36 \%$ for budesonide), taking into account different treatment endpoints. ${ }^{4,5,7,9,24,25}$

Our refractory patients were difficult to treat with dietary and second-line pharmacologic therapies, with less than half responding, even after multiple second line therapies. However, this population was small, and results should be interpreted with caution. The rate of medication non-adherence in our refractory patient population reinforces the importance of confirming that patients are taking and administering tCS properly. However, this noncompliance may also reflect patients with truly refractory disease discontinuing medications from which they do not receive benefit. Because we cannot differentiate these two groups (those whose non-compliance resulted in persistent disease and those who self-discontinued their medications due to a lack of effect) we included all non-responders to produce the most conservative estimates.

We found few clinical, endoscopic, or histologic predictors of steroid non-response. After multivariate analysis, patients who had abdominal pain at baseline were more likely to respond, while those requiring dilation at baseline were less likely to respond. The association of abdominal pain and improved clinical response is a new finding. One possible interpretation is that EoE may have different phenotypes, and the abdominal pain phenotype is easier to treat. It is also possible that the abdominal pain reflects an increased level of local inflammation that is more amenable to treatment with steroids. The underlying mechanism causing abdominal pain is not clear and merits further investigation.

The finding that the need for dilation at the time of disease presentation correlates to poor clinical outcomes is important. Dilation may be a proxy for the fibrostenotic phenotype of EoE, corresponding to later stage or more advanced disease, ${ }^{10,26}$ or it may correlate with a more aggressive form of the disease as our groups did not differ on symptom duration prior to diagnosis. Alternatively, dilation at baseline may decrease the efficacy of tCS by hastening clearance of the medication from the esophagus due to relief of distal obstruction.

There are relatively few data to help contextualize these results. Two small randomized controlled trials of steroid therapy in pediatric patients identified allergies and greater age, height, and weight as predictors of failure of steroid therapy. ${ }^{4,27}$ The only previous study of 
predictors of successful steroid therapy in adults was published in abstract form. On multivariate analysis, predictors of non-response were older age, the absence of food impaction, furrows, and dilation. ${ }^{28}$ While these were preliminary data, the finding that the need for baseline dilation predicts non-response is consistent with our findings. Clinicians should now recognize that strictures are a poor prognostic factor, and can use this finding to guide both patient counseling and plan of care.

A unique aspect of this study is the assessment of immunohistochemical predictors of steroid response. Those patients with high tissue levels of tryptase and eotaxin-3 at baseline were more likely to respond to tCS. This finding potentially opens new avenues of investigation, both to confirm these results and to understand the mechanisms. Previous research has shown that these biomarkers can help differentiate EoE from GERD, ${ }^{20}$ and eotaxin-3 levels have been shown to correlate with eosinophil counts and to decrease with steroid therapy. ${ }^{15}$ As of now, it is only possible to speculate whether patients with EoE and high mast cell levels might represent a tCS-responsive EoE sub-phenotype. If confirmed, these biomarkers may help differentiate steroid non-responders earlier in their course of care, allowing patients to be transitioned to alternate therapies earlier.

This study has several weaknesses. Because it is retrospective, not all outcomes are available in all patients and because some variables relied on chart review, there is the possibility of a non-differential classification bias. In addition, we rely on non-validated, binary (yes/no) measures of symptom and endoscopic response. This technique provided limited response detail in terms of individual symptoms and introduced the possibility of bias. While no validated measures of symptomatic or endoscopic response existed during the study time frame, and we have employed similar measures in other studies, ${ }^{29}$ interpretation of symptomatic and endoscopic outcomes should be done with caution. In addition, we chose $<15 \mathrm{eos} / \mathrm{hpf}$ as a cutoff for histologic response because it is consistent with the histologic cutpoint of $\geq 15$ eos/hpf which defines EoE. ${ }^{1-3}$ However, there is no consensus on what eosinophil count should be used to define response to therapy, and current guidelines do not define refractory EoE. ${ }^{3,30} \mathrm{We}$ also rely on a specific definition of refractory disease with a cutpoint of $\geq 30 \mathrm{eos} / \mathrm{hpf}$ with in combination with clinical factors to minimize misclassification occurring near the diagnostic cutpoint of 15 eos/hpf and to better identify those with severe disease.

This study also has multiple strengths. This is one of the largest cohorts reported to have treatment with tCS and follow-up, and has the power to assess predictors of steroid response. Additionally, we feel these response rates represent the real-world clinical effectiveness of these medications, rather than the efficacy measures reported in clinical trials, and therefore can be used by practitioners to inform patients of expected outcomes. Moreover, the use of baseline IHC staining to predict treatment outcomes provides novel findings and opens new areas of study.

In conclusion, while the majority of patients benefited from topical steroid therapy, nonresponse was common. For those who did not respond to steroid therapy, less than half were able to achieve disease response with other second-line therapies. There were few clinical, endoscopic, or histologic predictors of non-response, but the need for dilation at baseline 
was a strong independent predictor. Additionally, high esophageal tissue levels of eotaxin-3 and mast cells at baseline predicted treatment response, but this intriguing finding requires prospective confirmation before it can be adopted clinically.

\section{Acknowledgments}

Grant support: This research was supported, in part, by NIH awards T32DK007634 (WAW), P30DK034987 (WAW), K24DK100548 (NJS), and K23DK090073 (ESD)

\section{Abbreviations}

$\begin{array}{ll}\text { EoE } & \text { Eosinophilic esophagitis } \\ \text { eos/hpf } & \text { eosinophils per high powered field } \\ \text { EGD } & \text { esophagogastroduodenoscopy } \\ \text { GERD } & \text { gastroesophageal reflux disease } \\ \text { IHC } & \text { immunohistochemistry } \\ \text { MBP } & \text { major basic protein } \\ \text { tCS } & \text { topical corticosteroids }\end{array}$

\section{References}

1. Furuta GT, Liacouras CA, Collins MH, et al. Eosinophilic esophagitis in children and adults: a systematic review and consensus recommendations for diagnosis and treatment. Gastroenterology. 2007; 133:1342-1363. [PubMed: 17919504]

2. Liacouras CA, Furuta GT, Hirano I, et al. Eosinophilic esophagitis: updated consensus recommendations for children and adults. J Allergy Clin Immunol. 2011; 128:3-20. [PubMed: 21477849]

3. Dellon ES, Gonsalves N, Hirano I, et al. ACG clinical guideline: Evidenced based approach to the diagnosis and management of esophageal eosinophilia and eosinophilic esophagitis (EoE). Am J Gastroenterol. 2013; 108:679-92. quiz 693. [PubMed: 23567357]

4. Konikoff MR, Noel RJ, Blanchard C, et al. A randomized, double-blind, placebo-controlled trial of fluticasone propionate for pediatric eosinophilic esophagitis. Gastroenterology. 2006; 131:13811391. [PubMed: 17101314]

5. Dohil R, Newbury R, Fox L, et al. Oral viscous budesonide is effective in children with eosinophilic esophagitis in a randomized, placebo-controlled trial. Gastroenterology. 2010; 139:418-429.e1. [PubMed: 20457157]

6. Straumann A, Conus S, Degen L, et al. Budesonide is effective in adolescent and adult patients with active eosinophilic esophagitis. Gastroenterology. 2010; 139:1526-1537.e1. [PubMed: 20682320]

7. Alexander JA, Jung KW, Arora AS, et al. Swallowed fluticasone improves histologic but not symptomatic response of adults with eosinophilic esophagitis. Clinical Gastroenterology and Hepatology. 2012; 10:742-749.e1. [PubMed: 22475741]

8. Dellon ES. Diagnosis and management of eosinophilic esophagitis. Clin Gastroenterol Hepatol. 2012; 10:1066-1078. [PubMed: 22728382]

9. Dellon ES, Sheikh A, Speck O, et al. Viscous topical is more effective than nebulized steroid therapy for patients with eosinophilic esophagitis. Gastroenterology. 2012; 143:321-324.e1. [PubMed: 22561055]

10. Dellon ES, Kim HP, Sperry SL, et al. A phenotypic analysis shows that eosinophilic esophagitis is a progressive fibrostenotic disease. Gastrointest Endosc. 2013:586-8. 
11. Mishra A, Hogan SP, Brandt EB, et al. An etiological role for aeroallergens and eosinophils in experimental esophagitis. J Clin Invest. 2001; 107:83-90. [PubMed: 11134183]

12. Moawad F, Veerappan G, Lake J, et al. Correlation between eosinophilic oesophagitis and aeroallergens. Aliment Pharmacol Ther. 2010; 31:509-515. [PubMed: 19925501]

13. Hurrell JM, Genta RM, Dellon ES. Prevalence of esophageal eosinophilia varies by climate zone in the United States. Am J Gastroenterol. 2012; 107:698-706. [PubMed: 22310220]

14. Rothenberg ME. Biology and treatment of eosinophilic esophagitis. Gastroenterology. 2009; 137:1238-1249. [PubMed: 19596009]

15. Konikoff MR, Blanchard C, Kirby C, et al. Potential of blood eosinophils, eosinophil-derived neurotoxin, and eotaxin-3 as biomarkers of eosinophilic esophagitis. Clinical Gastroenterology and Hepatology. 2006; 4:1328-1336. [PubMed: 17059896]

16. Lu TX, Sherrill JD, Wen T, et al. MicroRNA signature in patients with eosinophilic esophagitis, reversibility with glucocorticoids, and assessment as disease biomarkers. J Allergy Clin Immunol. 2012; 129:1064-1075.e9. [PubMed: 22391115]

17. Caldwell JM, Blanchard C, Collins MH, et al. Glucocorticoid-regulated genes in eosinophilic esophagitis: a role for FKBP51. J Allergy Clin Immunol. 2010; 125:879-888.e8. [PubMed: 20371398]

18. Blanchard C, Stucke EM, Burwinkel K, et al. Coordinate interaction between IL-13 and epithelial differentiation cluster genes in eosinophilic esophagitis. J Immunol. 2010; 184:4033. [PubMed: 20208004]

19. Dellon ES, Chen X, Miller CR, et al. Tryptase staining of mast cells may differentiate eosinophilic esophagitis from gastroesophageal reflux disease. Am J Gastroenterol. 2010; 106:264-271. [PubMed: 20978486]

20. Dellon ES, Chen X, Miller CR, et al. Diagnostic utility of major basic protein, eotaxin-3, and leukotriene enzyme staining in eosinophilic esophagitis. Am J Gastroenterol. 2012; 107:15031511. [PubMed: 22777338]

21. Dellon ES, Gibbs WB, Fritchie KJ, et al. Clinical, endoscopic, and histologic findings distinguish eosinophilic esophagitis from gastroesophageal reflux disease. Clin Gastroenterol Hepatol. 2009; 7:1305-1313. [PubMed: 19733260]

22. Hirano I. Therapeutic end points in eosinophilic esophagitis: is elimination of esophageal eosinophils enough? Clinical Gastroenterology and Hepatology. 2012; 10:750-752. [PubMed: 22366179]

23. Aceves SS, Newbury RO, Chen D, et al. Resolution of remodeling in eosinophilic esophagitis correlates with epithelial response to topical corticosteroids. Allergy. 2010; 65:109-116. [PubMed: 19796194]

24. Straumann A, Degen L, Felder S, et al. Budesonide As Induction Treatment for Active Eosinophilic Esophagitis in Adolescents and Adults: A Randomized, Double-Blind, PlaceboControlled Study (Bee-I Trial). Gastroenterology. 2008; 134:A-104.

25. Gupta SK, Collins MH, Lewis JD, et al. Efficacy and Safety of Oral Budesonide Suspension (OBS) in Pediatric Subjects With Eosinophilic Esophagitis (EoE): Results From the Double-Blind, Placebo-Controlled PEER Study. Gastroenterology. 2011; 140(supplement 1):s179.

26. Schoepfer AM, Safroneeva E, Bussmann C, et al. Delay in Diagnosis of Eosinophilic Esophagitis Increases Risk for Stricture Formation, in a Time-Dependent Manner. Gastroenterology. 2013:1230-6. [PubMed: 23954315]

27. Noel RJ, Putnam PE, Collins MH, et al. Clinical and immunopathologic effects of swallowed fluticasone for eosinophilic esophagitis. Clinical Gastroenterology and Hepatology. 2004; 2:568575. [PubMed: 15224281]

28. Moawad F, Albert D, Heifert T, et al. Predictors of Non-Response to Topical Steroids Treatment in Eosinophilic Esophagitis. The American Journal of Gastroenterology. 2013; 108(Supplement 1):s14.

29. Wolf WA, Jerath MR, Sperry SL, et al. Dietary Elimination Therapy is an Effective Option for Adults with Eosinophilic Esophagitis. Clinical Gastroenterology and Hepatology. 2014 In Press.

30. Mukkada VA, Furuta GT. Management of Refractory Eosinophilic Esophagitis. Digestive Diseases. 2014; 32:134-138. [PubMed: 24603397] 

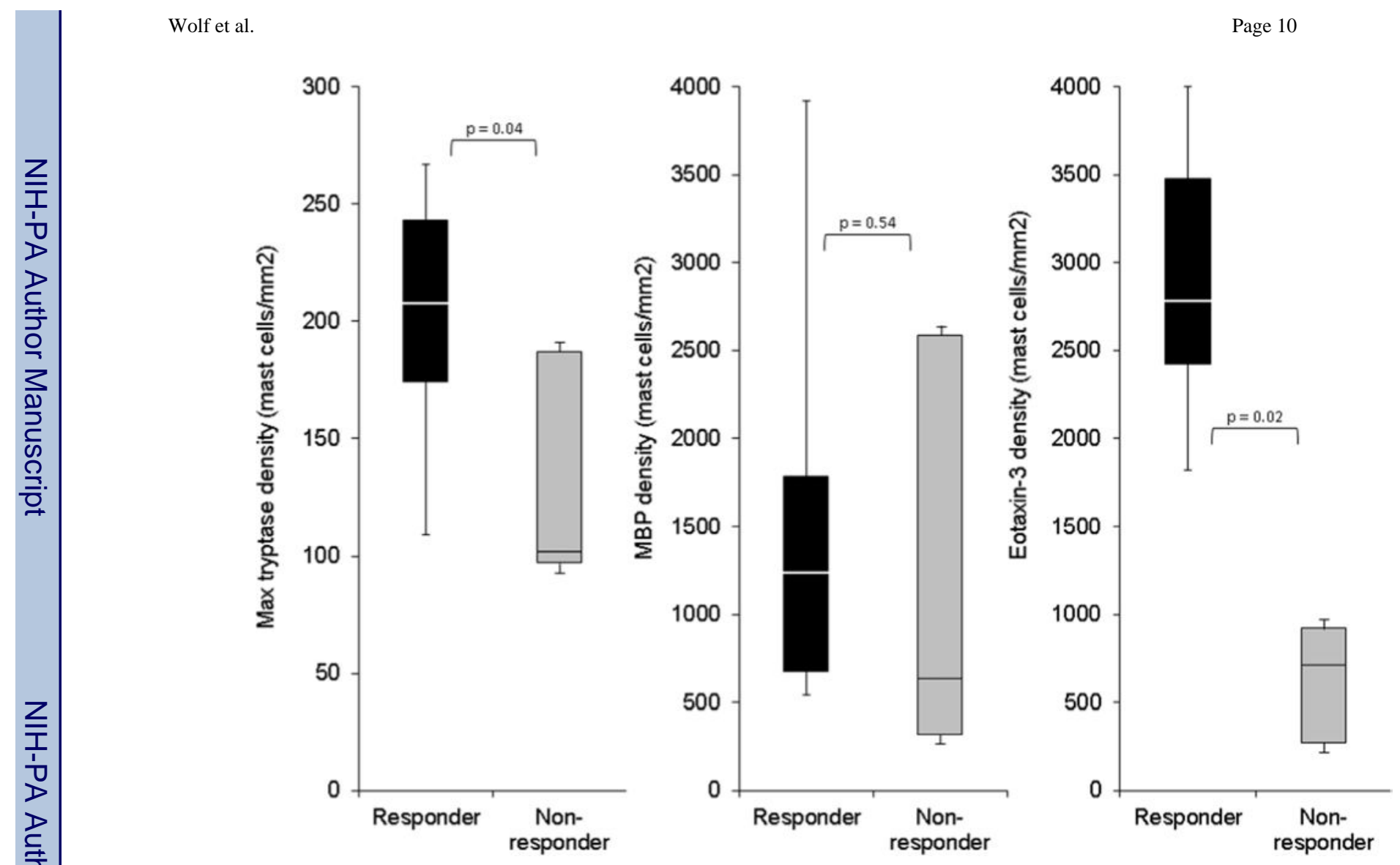

Figure 1.

Predicting steroid response with baseline IHC staining for tryptase, MBP, and eotaxin-3. For this box and whiskers plot, the horizontal line represents the median, the box represents the $25^{\text {th }}$ to $75^{\text {th }}$ percentiles, and the whiskers end at the maximum and minimum values. Steroid responders ( $<15$ eos/hpf) are in black bars, and non-responders $(\geq 15$ eos/hpf $)$ are in light gray bars. 


\section{Table 1}

Baseline Characteristics of the Study Population and Steroids Responders/Non-responders

\begin{tabular}{|c|c|c|c|c|}
\hline & $\begin{array}{l}\text { All Participants } \\
\qquad(\mathbf{n}=\mathbf{2 2 1})^{*}\end{array}$ & $\begin{array}{l}<15 \mathrm{eos} / \mathrm{hpf} \text { on steroids } \\
(\mathrm{n}=\mathbf{1 0 8})\end{array}$ & $\begin{array}{l}\geq 15 \mathrm{eos} / \mathrm{hpf} \text { on steroids } \\
\quad(\mathrm{n}=\mathbf{8 1})\end{array}$ & p-value \\
\hline Age, mean years \pm SD $($ range $)$ & $\begin{array}{l}25.6 \pm 18.0 \\
(0.6,78.3)\end{array}$ & $\begin{array}{c}28.0 \pm 18.9 \\
(1.4,78.3)\end{array}$ & $\begin{array}{l}24.9 \pm 17.0 \\
(0.6,72.2)\end{array}$ & 0.23 \\
\hline Adults $\geq 18$ years, $n(\%)$ & $129(58)$ & $64(59)$ & $53(65)$ & 0.39 \\
\hline Males, n (\%) & $155(70)$ & $77(71)$ & $56(69)$ & 0.75 \\
\hline Whites, n (\%) & $184(83)$ & $95(88)$ & $63(78)$ & 0.06 \\
\hline \multicolumn{5}{|l|}{ Symptoms (n, \%) } \\
\hline Dysphagia & $152(70)$ & $75(70)$ & $59(75)$ & 0.49 \\
\hline Food impaction & $70(32)$ & $35(33)$ & $26(33)$ & 0.98 \\
\hline Heartburn & $88(41)$ & $47(44)$ & $28(35)$ & 0.24 \\
\hline Chest pain & $25(12)$ & $16(15)$ & $6(8)$ & 0.12 \\
\hline Abdominal pain & $40(18)$ & $24(22)$ & $6(8)$ & 0.007 \\
\hline Nausea & $24(11)$ & $13(12)$ & $5(6)$ & 0.18 \\
\hline Vomiting & $62(29)$ & $31(29)$ & $19(24)$ & 0.43 \\
\hline Failure to thrive & $33(15)$ & $19(18)$ & $12(15)$ & 0.62 \\
\hline $\begin{array}{l}\text { Years of symptoms before diagnosis, mean } \pm \text { SD } \\
\text { (range) }\end{array}$ & $\begin{array}{c}7.5 \pm 9.3 \\
(0.0,53.0) \\
\end{array}$ & $\begin{array}{l}9.2 \pm 10.6 \\
(0.0,53.0) \\
\end{array}$ & $\begin{array}{c}6.5 \pm 7.9 \\
(0.0,45.0) \\
\end{array}$ & 0.12 \\
\hline \multicolumn{5}{|l|}{ Allergic diseases (n, \%) } \\
\hline Atopic Illness & $101(47)$ & $47(44)$ & $41(51)$ & 0.32 \\
\hline Asthma & $56(26)$ & $26(24)$ & $22(28)$ & 0.62 \\
\hline Food allergy & $57(29)$ & $31(31)$ & $20(26)$ & 0.47 \\
\hline Any allergic disease & $125(58)$ & $60(56)$ & $47(59)$ & 0.71 \\
\hline \multicolumn{5}{|l|}{ Endoscopic findings (n, \%) } \\
\hline Normal & $22(10)$ & $10(9)$ & $5(6)$ & 0.43 \\
\hline Rings & $101(46)$ & $47(44)$ & $46(57)$ & 0.08 \\
\hline Stricture & $45(20)$ & $19(18)$ & $22(27)$ & 0.12 \\
\hline Narrowing & $38(17)$ & $13(12)$ & $23(28)$ & 0.005 \\
\hline Linear furrows & $110(50)$ & $56(52)$ & $50(62)$ & 0.20 \\
\hline White plaques & $61(28)$ & $31(29)$ & $26(32)$ & 0.64 \\
\hline Decreased vascularity & $58(26)$ & $30(28)$ & $27(33)$ & 0.43 \\
\hline Crêpe-paper mucosa & $13(6)$ & $7(7)$ & $6(7)$ & 0.82 \\
\hline Hiatal hernia & $21(10)$ & $9(8)$ & $8(10)$ & 0.71 \\
\hline Dilation performed & $55(25)$ & $20(19)$ & $30(37)$ & 0.006 \\
\hline Maximum eosinophil count, mean \pm SD (range) & $\begin{array}{c}79 \pm 66 \\
(15,469)\end{array}$ & $\begin{array}{l}76 \pm 65 \\
(15,430)\end{array}$ & $\begin{array}{c}75 \pm 56 \\
(15,333)\end{array}$ & 0.85 \\
\hline
\end{tabular}


Table 2

Steroid Treatment and Response

\begin{tabular}{|c|c|c|c|c|}
\hline & $\begin{array}{l}\text { All Participants } \\
\qquad(\mathbf{n}=\mathbf{2 2 1})^{*}\end{array}$ & $\begin{array}{l}<15 \mathrm{eos} / \mathrm{hpf} \text { on steroids } \\
\quad(\mathrm{n}=\mathbf{1 0 8})\end{array}$ & $\begin{array}{l}\qquad 15 \mathrm{eos} / \mathrm{hpf} \text { on steroids } \\
\qquad(\mathrm{n}=\mathbf{8 1})\end{array}$ & p-value \\
\hline Type of topical steroid, $n(\%)$ & & & & 0.48 \\
\hline Fluticasone & $81(37)$ & $27(25)$ & $24(30)$ & \\
\hline Budesonide & $140(63)$ & $81(75)$ & $57(70)$ & \\
\hline \multicolumn{5}{|l|}{$\begin{array}{l}\text { Total daily dose of topical steroid, mean mcg } \pm \\
\text { SD }\end{array}$} \\
\hline Fluticasone & $1100 \pm 604$ & $1279 \pm 567$ & $1247 \pm 641$ & 0.89 \\
\hline Budesonide & $1686 \pm 690$ & $1722 \pm 671$ & $1654 \pm 705$ & 0.49 \\
\hline $\begin{array}{l}\text { Steroid therapy max eosinophil count, mean } \pm \\
\text { SD (range) }\end{array}$ & $27 \pm 40(0,200)$ & $2 \pm 3(0,14)$ & $61 \pm 41(15,200)$ & $<0.0001$ \\
\hline$\%$ change in eos, mean \pm SD (range) & $-51 \pm 79(-100,355)$ & $-97 \pm 6(-100,-73)$ & $10 \pm 89(-88,355)$ & $<0.0001$ \\
\hline \multicolumn{5}{|l|}{ Response to tCS, n (\%) } \\
\hline Symptom response & $150(79)$ & $82(87)$ & $38(60)$ & $<0.0001$ \\
\hline EGD response & $137(71)$ & $99(92)$ & $34(42)$ & $<0.0001$ \\
\hline \multicolumn{5}{|l|}{ Endoscopy Findings on Steroid Therapy, n (\%) } \\
\hline Normal & $45(23)$ & $38(35)$ & $7(9)$ & $<0.0001$ \\
\hline Rings & $78(41)$ & $37(35)$ & $40(49)$ & 0.052 \\
\hline Stricture & $37(20)$ & $9(9)$ & $26(32)$ & $<0.0001$ \\
\hline Narrowing & $30(16)$ & $8(8)$ & $21(26)$ & 0.0008 \\
\hline Linear furrows & $73(39)$ & $19(18)$ & $53(65)$ & $<0.0001$ \\
\hline White plaques & $37(20)$ & $7(7)$ & $30(37)$ & $<0.0001$ \\
\hline Decreased vascularity & $46(24)$ & $18(17)$ & $28(35)$ & 0.007 \\
\hline Crêpe-paper mucosa & $1(1)$ & $0(0)$ & $1(1)$ & 0.26 \\
\hline Dilation performed & $46(24)$ & $12(12)$ & $31(38)$ & $<0.0001$ \\
\hline Candida present & $10(5)$ & $8(8)$ & $2(3)$ & 0.12 \\
\hline
\end{tabular}


Table 3

Predictors of Non-Response to TCS from Multivariate Logistic Regression

\begin{tabular}{lcc}
\hline & Main Effects Model OR [95\% CI] & Adjusted OR [95\% CI] \\
\hline White Race & $0.42[0.18-0.97]$ & $0.54[0.22-1.29]$ \\
\hline Abdominal Pain & $0.32[0.12-0.85]$ & $0.31[0.12-0.83]$ \\
\hline Dilation Performed & $2.4[1.2-4.8]$ & $2.9[1.4-6.3]$ \\
\hline
\end{tabular}

* Adjusted for age, baseline eosinophil count, and known allergic disease; OR > 1.0 indicates increased odds of not responding to steroids. 
Table 4

Second-Line Therapies for Refractory Patients $(n=27)$

\begin{tabular}{lc}
\hline Therapy (n receiving) & Responded with $<15$ eos (n, \%) \\
\hline Dietary (16) & $6(38)$ \\
\hline Increased dose (14) & $2(14)$ \\
\hline Changed topical agent (7) & $2(29)$ \\
\hline Singular (7) & $1(14)$ \\
\hline Prednisone (5) & $1(20)$ \\
\hline Ciclesonide (3) & $0(0)$ \\
\hline Compounded budesonide (2) & $1(50)$ \\
\hline Ketotifen (1) & $0(0)$ \\
\hline 6 MP (1) & $0(0)$ \\
\hline Total & $13(48)$ \\
\hline
\end{tabular}

